\title{
A VULNERABILIDADE DOS PESCADORES ARTESANAIS BRASILEIROS: UMA ANÁLISE SOCIODEMOGRÁFICA
}

\section{The vulnerability of Brazilian artisanal fishermen: a sociodemographic analysis}

\author{
Rafael Barsotti Torres \\ Escola Nacional de Ciências Estatísticas/IBGE \\ rafaelbrtorres@gmail.com \\ Letícia de Carvalho Giannella \\ Escola Nacional de Ciências Estatísticas/IBGE \\ leticiagiannella@gmail.com
}

\section{Recebido em 02/10/11/2020 \\ Aceito em 13/11/2020}

RESUMO: Categoria de fundamental importância no âmbito da pesca profissional no país, os pescadores artesanais vivem, todavia, em condições de vulnerabilidade frente a diversos processos de vulnerabilização que permeiam sua própria reprodução social e cultural. Assim, o objetivo deste artigo é realizar uma análise sociodemográfica desses trabalhadores a fim de contribuir para a elaboração de políticas públicas voltadas à superação de suas condições de vulnerabilidade. Para tanto, refletiu-se sobre a pesca artesanal brasileira, primeiramente, a partir de literatura especializada sobre a temática, com o auxílio dos conceitos de risco, perigo, vulnerabilidade e vulnerabilização. Complementarmente, utilizando o software $R$-Studio versão 1.1.463, analisou-se regionalmente as características sociodemográficas e dos domicílios dos pescadores artesanais brasileiros a partir dos microdados da Pesquisa Nacional por Amostra de Domicílios Contínua (PNADC) anual de 2018. Concluiu-se que esse grupo apresenta características, regionalmente discrepantes, que denotam sua condição de vulnerabilidade que, por sua vez, é acentuada por processos de vulnerabilização, tais como degradação ambiental, industrialização, urbanização, sobrepesca, entre outros, que também apresentam ocorrência diferenciada pelo Brasil. Assim, é preciso que políticas públicas que venham a ser pensadas para esses trabalhadores considerem a complexidade de fatores que configuram tal condição, incluindo as discrepâncias inter-regionais da categoria, incrementando sua capacidade de resposta aos riscos e perigos.

Palavras-chave: Pescadores Artesanais; Vulnerabilidade; Análise Sociodemográfica; PNADC.

\begin{abstract}
A category of fundamental importance in the context of professional fishing in the Brazil, artisanal fishers live in condition of vulnerability threatened by various vulnerability processes that permeate their own social and cultural reproduction. This article aims to produce a sociodemographic analysis about these workers in order to subsidize the elaboration of public policies that aim to overcome their vulnerability condition. Therefore, firstly, this paper reflected about the Brazilian artisanal fishing from specialized literature on the subject, with the help of the concepts of risk, danger, vulnerability and vulnerability processes. In addition, using the software R-Studio version 1.1.463, the regional sociodemographic and household characteristics of Brazilian artisanal fishers were quantitatively analyzed using the 2018 Pesquisa Nacional por Amostra de Domicílios Contínua (PNADC) microdata. This article concludes that this group has characteristics that denote their vulnerability condition, with regional differences in Brazil's territory, which are reinforced by vulnerability processes, such as environmental degradation, industrialization, urbanization, overfishing, among others, which also have regional differences in their occurrence. Therefore, it is necessary that public policies that focus on these workers consider the complexity of factors that configure such condition, including the interregional discrepancy, improving their responsiveness to risks and dangers.
\end{abstract}

Keywords: Artisanal fishers; Vulnerability; Sociodemographic analysis; PNADC. 


\section{INTRODUÇÃO}

A pesca no Brasil tem influência de tradições indígenas, africanas e de técnicas europeias (DIEGUES, 2004). A atividade pesqueira profissional exercida atualmente em território nacional pode ser dividida nas modalidades artesanal e industrial, apresentando, todavia, características díspares quanto aos seus atributos e perfis ocupacionais.

Os pescadores artesanais brasileiros constituem uma categoria de fundamental importância no âmbito da pesca no país. Apresentando grande maioria da força de trabalho do setor (SILVA, 2014) e espalhados pelas regiões brasileiras, esta modalidade se constituiu historicamente como atividade essencial para 0 abastecimento interno de pescado no Brasil, garantindo uma rica fonte de alimentos para a população brasileira e de renda para inúmeras famílias de pescadores.

Apesar de sua importância, fatores como degradação ambiental, sobrepesca intensiva praticada principalmente pela pesca industrial, mudanças climáticas, urbanização, especulação imobiliária, industrialização da zona costeira, transporte marítimo de substâncias tóxicas, entre outros, configuram-se como potenciais causadores de riscos e perigos aos pescadores artesanais em escala nacional.

Recentemente, assistiu-se a um dos maiores desastres ambientais em extensão já registrado em nosso território. Trata-se do vazamento de óleo no litoral do país, ocorrido no segundo semestre de 2019, e que já atingiu, até o momento, toda a costa nordestina e parte do Sudeste (UCHÔA, 2019a). Uma das suas consequências mais cruéis é o agravamento brutal da vulnerabilidade dos pescadores artesanais da nossa zona costeira, que se encontram impedidos de pescar devido à provável contaminação química das espécies marinhas. Este caso é emblemático dos riscos, perigos e processos de vulnerabilização a que esses trabalhadores estão sujeitos em sua faina cotidiana.

Contrariamente a esses processos que os ameaçam, os pescadores artesanais, como as populações tradicionais em geral, têm assumido papel preponderante na manutenção dos recursos naturais e na organização de movimentos voltados à preservação ambiental. O protagonismo destas populações frente ao quadro de agravo da crise ambiental brasileira, inclusive demandando a criação de determinadas Unidades de Conservação, como as Reservas Extrativistas Marinhas (SILVA, 2004), tornam os trabalhadores da pesca artesanal uma categoria de grande relevância dentro do movimento brasileiro (DIEGUES, 2004).

Assim, torna-se fundamental a produção de informações que subsidiem as políticas direcionadas à pesca artesanal brasileira, a partir de dois elementos: a identificação das condições de vulnerabilidade e dos processos de vulnerabilização (ACSELRAD, 2006; 2015) desses trabalhadores tão relevantes para a sociedade. É necessário compreender quais são as características que os configuram como vulneráveis e os processos que reforçam e aprofundam essas condições para que se possa construir políticas voltadas à superação desta situação. 
Assim, em termos de condições de vulnerabilidade referimo-nos aqui tanto aos atributos sociodemográficos desse grupo, tais como renda, escolaridade, alfabetização, cor/raça, entre outros; quanto aos atributos dos espaços onde eles se territorializam, quais sejam: infraestrutura urbana, características dos domicílios, insegurança fundiária etc, isto é, elementos externos aos pescadores, mas que reforçam sua condição de vulnerabilidade. Os processos de vulnerabilização, por outro lado, são entendidos aqui como práticas políticas e político-institucionais que fragilizam seus laços comunitários, desorganizam suas práticas espaciais e comprometem sua reprodução social, entendida aqui como socioespacial (SANTOS, 1977). São conflitos, disputas, tensões com empreendimentos das escalas mais variadas por quais passam cotidianamente diversas comunidades de pesca pelo país. Por fim, é essencial observar também a limitação das políticas públicas recentes voltadas à pesca artesanal, muito pontuais e centradas na dimensão econômica, e seu recente processo de desmonte, realçando ainda mais sua vulnerabilidade.

O presente artigo objetiva contribuir para a produção dessas informações, analisando geograficamente as características pontuadas acima. Nossa ênfase estará na caracterização sociodemográfica desse grupo como um todo e também a partir de recortes regionais, evidenciando as discrepâncias entre os pescadores das diversas macrorregiões brasileiras. A caracterização sociodemográfica se dará a partir da Pesquisa Nacional por Amostra de Domicílios Contínua (PNADC). As informações e análises extraídas e realizadas a partir da pesquisa serão relacionadas aos riscos, perigos e processos de vulnerabilização à atividade e aos territórios artesanais, nesse caso utilizando de revisão bibliográfica. $\mathrm{Na}$ análise dos processos de vulnerabilização, também se tentará apontar as diferenças e contrastes regionais, isto é, as práticas de vulnerabilização mais acentuadas regionalmente, construindo, portanto, um arcabouço que permita a identificação de suas características e do quadro de vulnerabilidade que assola essa população.

\section{METODOLOGIA}

A pesquisa baseou-se numa análise quali-quantitativa do recorte ocupacional proposto. Em relação aos aspectos qualitativos, buscou-se analisar a pesca artesanal brasileira tendo como referencial empírico a literatura especializada na temática e como referencial teórico-conceitual o debate sobre risco, perigo, vulnerabilidade e vulnerabilização.

A dimensão quantitativa deste artigo envolveu o uso da PNADC referente ao ano de 2018, à qual foram realizados alguns recortes no tratamento dos dados a fim de restringir o universo de estudo aos pescadores artesanais brasileiros. Tal recorte foi dimensionado com base na legislação que normatiza e define a categoria da "pesca artesanal" como forma de produção

praticada diretamente por pescador profissional, de forma autônoma ou em regime de economia familiar, com meios de produção próprios ou mediante contrato de parceria, desembarcado, podendo utilizar embarcações de pequeno porte (BRASIL, 2009, grifo nosso). 
Desta maneira, a delimitação do universo de estudo empregado na pesquisa, utilizando os microdados da "visita 1" - dado seu foco nas condições de habitação e socioeconômicas dos entrevistados, foi realizada a partir das respostas: "Pescador" à variável "Código da ocupação (cargo ou função)"; "Conta própria" ou "Trabalhador familiar não remunerado" à variável acerca da posição na ocupação ("Nesse trabalho, ... era"); e finalmente a resposta "Não" a se o negócio/empresa em que era ocupado tinha "registro no Cadastro Nacional da Pessoa Jurídica - CNPJ" (IBGE, 2019, p.34), a fim de realizar um recorte mais apurado do grupo de pescadores artesanais, evitando a mistura com trabalhadores da pesca industrial no universo de análise. Isto é, foram selecionados os pescadores que trabalhavam em regime de economia familiar ou por conta própria e, no caso destes últimos, que não trabalhavam em organização com Cadastro Nacional da Pessoa Jurídica.

Dentre as opções da PNADC, foram analisadas, para as macrorregiões brasileiras, as variáveis ligadas à dimensão étnico/racial e estatuto socioeconômico (cor/raça; renda mensal habitualmente recebida do trabalho principal e distribuição da categoria em faixas de rendimento; rendimento de todas as fontes; e rendimento domiciliar efetivo per capita); à infraestrutura domiciliar e urbana (condição do esgoto sanitário; principal forma de abastecimento de água; e forma de destinação do lixo); e ao capital humano dos pescadores artesanais (condição de alfabetização; frequência à escola; maior nível de instrução alcançado) (IBGE, 2019a), segundo as propostas de Cutter (2011) e IPEA (2018). Por uma limitação metodológica da PNADC, não foi possível realizar uma comparação a partir de níveis político-administrativos menores, como as Unidades da Federação.

Importante apontar que em todas as variáveis e respostas consideradas foram calculados o coeficiente de variação a fim de se tentar estabelecer um critério de análise, tornando o mais acurado possível as estimativas das características e condições de vida dos pescadores artesanais. Dessa maneira, indicada a variabilidade menor dos dados, foram aceitas e utilizadas para análise as respostas às variáveis que obtiveram o coeficiente menor ou igual a $30 \%$. Todas as operações estatísticas e o tratamento dos dados da PNADC foram realizados no software $R$ Studio, versão 1.1.463.

Tratando sobre o arcabouço conceitual deste artigo, o conceito de vulnerabilidade, primeiramente, "é fundamental ter em mente a pergunta 'vulnerabilidade a que?' quando se procede a uma investigação. A vulnerabilidade sempre será definida a partir de um perigo ou um conjunto deles, em dado contexto geográfico e social" (MARANDOLA JR. e HOGAN, 2006, p. 36).

Uma vez que a vulnerabilidade não se define por si, mas sim sempre em relação aos riscos/perigos, importa esclarecer o significado destes termos, ainda que existam abordagens conceituais distintas segundo filiações teóricas e contextos geográficos específicos. Adota-se, aqui, a definição de Castro (2000), para quem o risco se configura como a probabilidade de ocorrência de um perigo, podendo ou não ser quantificado. O perigo, segundo Castro (2000), é a ocorrência ou ameaça de ocorrência de um acontecimento danoso, isto é, um "fenômeno tanto em ato como em 
potência" (não paginado). A autora ainda discute, também, o conceito de desastre, que seria o conjunto de danos resultantes do perigo.

No decorrer das últimas décadas, diversos estudos resultaram na construção de um rico arcabouço conceitual a respeito das noções de risco, perigo e vulnerabilidade. Mais recentemente, pesquisadores brasileiros que atuam especialmente na interface geografia-sociologia - como Henri Acselrad - vem buscando dialogar e problematizar essas abordagens à luz do que é denominado como vulnerabilidade, perspectiva na qual a pesquisa que deu origem ao presente artigo está alicerçada.

Nesta ótica, a vulnerabilidade articula as dimensões sociodemográfica e os processos de vulnerabilização, frequentemente ligados aos territórios. Nesta perspectiva, estudar a vulnerabilidade implica na análise de características e processos tais como: composição demográfica, migração, estrutura socioeconômica, estrutura fundiária, metropolização, condições biofísicas, degradação ambiental, sistemas de proteção social, ativos e estruturas de oportunidades - "elementos do capital social que não têm vinculação com poder aquisitivo nem renda" (MARANDOLA JR. e HOGAN, 2005, p. 43) -, entre outros. A pesquisa aqui proposta acrescentará elementos de caráter iminentemente político, como conflitos e disputas em torno de elementos normalmente ligados ao território. Logo, tratar-se-á essencialmente de uma abordagem multidimensional.

É importante destacar também que a vulnerabilidade não é uma condição estática e nem mesmo resultado de escolhas dos indivíduos. A vulnerabilidade é uma relação, um processo, e deve ser considerada, portanto, à luz da vulnerabilização, ou seja, das práticas político-institucionais que vulnerabilizam certos grupos sociais (ACSELRAD, 2006, 2010). O movimento por justiça ambiental, nascido nos anos 1980 nos Estados Unidos, tem como argumento central a constatação de que determinados grupos sociais são sempre sacrificados e suas condições de vulnerabilidade são sempre aguçadas frente a todo tipo de riscos que lhes são impostos. Segundo Acselrad (2015),

recursos urbanos e ambientais que permitem aos sujeitos protegerem-se dos agravos - incluindo-se aqueles recursos que não são objeto de apropriação privada - têm seu acesso desigualmente distribuído, configurando uma condição que é, por sua vez, com frequência atravessada por um diagrama de forças e por processos conflitivos (p. 58).

De tal maneira, os conflitos socioambientais podem ser entendidos também como indicadores de insustentabilidade das cidades e regiões, podendo ser invisibilizados e até neutralizados, através de forças coercitivas e do cooptação, por exemplo, ou podem ser "reconhecidos, discutidos e politizados" (p. 66). Nesse sentido, o enfrentamento das condições e processos de vulnerabilização, a partir de sua compreensão enquanto forma política, seria um caminho elementar para a construção de uma efetiva "sustentabilidade" nas cidades.

Deste modo, ao analisarmos a vulnerabilidade dos pescadores artesanais, é preciso também colocar em relevo, ainda que brevemente, condições e processos que reforçam e produzem continuamente essa condição. 


\section{RESULTADOS E DISCUSSÕES}

\section{Pescadores artesanais brasileiros: características e processos de vulnerabilização da categoria}

A lei que regulamenta o setor no Brasil - a Política Nacional de Desenvolvimento Sustentável da Pesca e Aquicultura, Lei o 11.959, de 29 de junho de 2009 categoriza as modalidades da atividade pesqueira artesanal e industrial como "comercial". Como disposto na supracitada lei, a pesca artesanal tem como atributos o emprego de mão-de-obra de pescadores profissionais, de forma autônoma, em regime de trabalho familiar e/ou organizados em relações de parceria, sem vínculo empregatício, com instrumentos de produção próprios ou vinculados a acordos de parceria, se utilizando de pequenas embarcações.

Espalhadas pela costa brasileira, margens de rios e lagoas, seus núcleos concentram trabalhadores ligados às diversas etapas da pesca, como tecelões de rede, mecânicos e restauradores de embarcações, além dos próprios pescadores (SILVA, 2015). Apesar de sua aglomeração nestes trechos, é incomum a formação de centros econômicos e áreas de grande dinamismo comercial, sendo mais frequente a formação de vilarejos, muitas vezes empobrecidos, que eventualmente dão origem a pequenas cidades e núcleos cuja principal atividade é a pesca de pequena escala (ARAÚJO et al., 2014).

Nas últimas décadas os pescadores artesanais e suas famílias foram incluídos em uma série de políticas públicas e programas sociais, de universo mais amplo ou mesmo direcionados ao setor pesqueiro, voltados ao combate da pobreza e, de forma mais ampla, à redução das desigualdades sociais. Dentre eles destacam-se o Bolsa Família, o Seguro Desemprego do Pescador Artesanal (Seguro-Defeso), sua categorização como Segurado Especial no Regime da Previdência Social , entre outros (SILVA, 2015). Essas políticas, centradas na dimensão econômica, tiveram impactos pontuais para os pescadores, de modo que poucas foram as mudanças nas condições de vida da categoria nos últimos anos (OLIVEIRA; SILVA, 2012; RAMALHO, 2014).

Em relação ao escoamento da produção, a falta de estrutura de processamento e transporte faz com que a ação de atravessadores ainda seja muito frequente nessa cadeia produtiva. Esta condição impõe uma realidade onde, apesar do alto valor comercial do pescado se comparado a outras fontes de proteína animal, os pescadores artesanais têm baixa percepção de renda, passível de caracterização como pobreza monetária (BÉNÉ; FRIEND, 2011).

Fonte de inspiração para a literatura e o cancioneiro brasileiro - "é doce morrer no mar..." -, o perigo fundamental que acompanha a faina cotidiana de todo pescador artesanal e suas famílias é o de perder suas vidas para o mar, imprevisível e invencível nas "batalhas entre homem e natureza". O risco constante de "morrer no mar" torna a 
relação com a natureza uma relação pautada no profundo respeito aos seus ciclos, dinâmicas e simbolismos. Apesar disso, tal risco pode ser atenuado ou aumentado em função das técnicas de pesca empregadas na atividade, especialmente no que se refere ao tamanho e estrutura dos barcos de posse dos pescadores. Assim, tem-se que, quanto menor a capacidade de investimento em técnicas pesqueiras que possam preservar a vida desses trabalhadores, maior é a sua vulnerabilidade (DIEGUES, 2004). Nesse sentido, assim como a omissão do Estado no auxílio às etapas de processamento, transporte e comercialização, a ausência de políticas públicas e linhas de financiamento destinadas a esse fim, a confecção e investimento em embarcações mais seguras, pode ser entendido como mais um processo de vulnerabilização atingindo os grupos e comunidades em escala nacional.

De forma generalizada, pode-se dizer que um segundo fator potencial gerador de perigo para os pescadores artesanais é a degradação ambiental que, por sua vez, é resultado de processos materiais estreitamente vinculados à reprodução do modo de vida hegemônico. Este grupo depende intimamente da saúde ambiental para a sua própria reprodução, posto que seu sustento advém diretamente da natureza.

O risco advém da poluição dos corpos hídricos decorrente do lançamento de efluentes industriais - na maior parte das vezes carregando altos níveis de toxicidade - e domésticos, além de resíduos sólidos, petróleo, microplásticos, pesticidas etc., somada, no caso de rios, à retirada das suas matas ciliares, resultando em processos como assoreamento, eutrofização e contaminação, que alteram profundamente os ecossistemas (FARACO et. al, 2016). Tais alterações redundam na perda de abundância, riqueza e biodiversidade aquática que leva, em um primeiro momento, à pauperização dos recursos pesqueiros e, no limite, ao perigo da impossibilidade de exercício da pesca por aqueles sujeitos. Associado a isso, considera-se ainda que poucos são os recursos - materiais, simbólicos, jurídicos, políticos etc. - a que esses pescadores tem acesso para frear o processo de degradação do seu ambiente, interrompendo a reprodução da sua situação de vulnerabilidade. Os casos mais frequentes desta forma de vulnerabilização parecem concentrados nas regiões mais urbanizadas e industrializadas do país, principalmente nas macrorregiões Sul e Sudeste (DIEGUES, 1983, 2004; FAUSTINO; FURTADO, 2013), o que não impede a ocorrência destes processos nas demais regiões como Nordeste e Norte (RIBEIRO; CASTRO, 2016).

Ademais, é preciso ter em conta que os corpos d'água fazem parte, nos oceanos, do meio marítimo e, no continente, de bacias hidrográficas que, por sua vez, conectamse em diversas escalas. Deste modo, os processos que levam à degradação ambiental do território de determinada comunidade de pescadores artesanais escapam à sua apreensão e controle imediato. Bom exemplo, já citado, é o do derramamento de óleo de fonte desconhecida que têm contaminado centenas de praias e enormes trechos do litoral nordestino, com grande imprevisibilidade sobre seu deslocamento e futuras contaminações (UCHÔA, 2019b).

A industrialização da zona costeira, além de ser um dos principais processos responsáveis pela degradação ambiental discorrida acima, também é muitas vezes 
responsável por delimitar, de forma absoluta, territórios onde a pesca torna-se proibida, como é o caso da "grande área de exclusão da pesca" instituída pelas indústrias petroquímicas instaladas ao redor da Baía de Guanabara (FAUSTINO; FURTADO, 2013). Outrossim, os riscos que a instalação dessas indústrias representa para a saúde ambiental/humana são muitas vezes invisibilizados. Neste cenário, os pescadores artesanais são frequentemente induzidos a abandonar sua ocupação, aceitando empregos precarizados e, geralmente, temporários nesses novos complexos produtivos, o que, por seu turno, gera rupturas sociais e geracionais associadas à desconstrução do modo de vida tradicional, elos e vínculos comunitários, reforçando sua vulnerabilidade (DIEGUES, 2004).

Processo que nasce do ventre da industrialização (LEFÈBVRE, 1999), a urbanização pode ser entendida hoje como um fator central associado à vulnerabilidade dos pescadores artesanais no nosso território. O vínculo urbanização-industrializaçãodegradação ambiental é claro e está implícito nos parágrafos anteriores. Cabe ressaltar aqui, portanto, os demais fatores associados à produção do urbano que acentuam a vulnerabilidade dos pescadores artesanais.

Devido à ausência histórica de políticas direcionadas à habitação, com enorme frequência, os pescadores artesanais vivem atualmente em domicílios carecendo da titulação da propriedade, inseridos em áreas de expansão da malha urbana (SILVA, 2015), em geral com pouco acesso a serviços e disponibilidade de equipamentos públicos. A metropolização do espaço (LENCIONI, 2013) vem atuando no sentido de reforçar essas vulnerabilidades, apresentando novos riscos e perigos aos pescadores artesanais. Essa nova fase da urbanização, centrada na articulação entre setor imobiliário e financeiro, gerou especulação imobiliária e afastou ainda mais a possibilidade dos trabalhadores acessarem terras infraestruturadas e bem localizadas (FIX, 2011).

Neste cenário de metropolização excludente, a expansão de condomínios fechados e outros produtos do setor imobiliário voltados às classes altas vem avançando sobre o litoral brasileiro, ameaçando a reprodução de grupos como os pescadores artesanais, dependentes da pequena renda oriunda de sua ocupação e de soluções coletivas, como a autoconstrução, formando periferias com escassa infraestrutura e equipamentos públicos. Por fim, é importante ressaltar os riscos e perigos oriundos da atividade de portos, redes e terminais logísticos na paisagem de grandes regiões metropolitanas litorâneas do país.

Esse processo de urbanização/metropolização representa, para os pescadores artesanais, um perigo permanente relacionado à ameaça de inviabilização da sua atividade e, portanto, da sua própria reprodução. Historicamente, constituiu-se para esse grupo uma situação de insegurança fundiária que, frente aos processos de especulação imobiliária, tornam-lhes mais e mais vulneráveis quanto à permanência em seus territórios tradicionais. Esse processo, ligado à expansão da malha urbana alicerçada na especulação imobiliária, também se mostra mais avançado nas regiões mais urbanizadas do país, como Sul e Sudeste (DIEGUES, 2004). Contudo, na última década, sua expansão em localidades turísticas da região Nordestes tem ganho muito 
destaque, mostrando-se um processo de vulnerabilização de grande intensidade (RODRIGUIES, 2010; ARAÚJO; SASSI; LIMA, 2014).

Tanto o Estado quanto o setor privado disputam suas terras, situadas muitas vezes em porções do território brasileiro consideravelmente valorizadas, e poucos são os recursos econômicos e jurídicos que lhes cabem para que saiam vencedores dessas disputas (RODRIGUES, 2010), restando apenas a organização política e os movimentos de luta pelo atendimento de seus direitos e reinvindicações. A urbanização de seus territórios também, paradoxalmente, não implica necessariamente na melhoria das suas condições de habitabilidade. Evidenciar-se-á na próxima seção que as condições dos domicílios dos pescadores artesanais brasileiros configuram-se como condições precárias que indicam sua condição de vulnerabilidade.

Com o crescimento exponencial da atividade turística no litoral brasileiro, os pescadores tiveram, assim, sua atividade laboral transformada, passando a exercer funções ligadas ao setor terciário da economia, muitas vezes mal remuneradas e com pouca exigência de qualificação. Isso tudo representa, portanto, além de restrições materiais à realização da atividade pesqueira, alterações culturais profundas que tem como uma de suas consequências a ruptura geracional (KANT DE LIMA; PEREIRA, 1997), o que pode apontar para um futuro nem tão distante onde a pesca artesanal se torne uma atividade residual e altamente precarizada.

Além disso, os pescadores artesanais sofreram, ao longo do século $\mathrm{XX}$, grande desorganização de sua cadeia produtiva devido ao advento da pesca industrial. Este segmento, capitalizado e aparelhado com modernos equipamentos de navegação, localização e captura de cardumes, representou uma ameaça à reprodução social dos pescadores artesanais, decorrente, sobretudo, da competição pelos estoques pesqueiros com sua consequente redução. Este é hoje mais um risco sofrido pelos pescadores artesanais: a cíclica redução da biomassa de pescado devido à sobrepesca, em grande parte causada pela atividade de pesca industrial (DIAS NETO, 2010), centrada, sobremaneira, na região Sul e Sudeste, devido à concentração da frota industrial do país nestas regiões (DIEGUES, 1983; FARACO et al., 2016), mas também perceptível na região Norte, principalmente na foz do Rio Amazonas (DIAS NETO, 2010), e em trechos da região Nordeste (PEDROSA; LIRA; MAIA, 2013). Além destes, pode-se citar outras atividades produtivas do setor como geradoras de riscos e perigos para os pescadores, como a aquicultura e carcinocultura (RAMALHO, 2014), essas centradas, sobretudo, na região Nordeste, devido à concentração de empreendimentos nos trechos de estuários de rios da região.

As mudanças climáticas globais devem também ser incluídas como um perigo real para a existência e reprodução dos pescadores artesanais. Situados em grande parte na zona costeira, esses trabalhadores não possuem recursos materiais e societários para construir estratégias de resistência frente à provável elevação do nível médio do mar, podendo tornar-se no futuro refugiados ambientais. Tratam-se de grupos territorializados há gerações em determinadas parcelas do espaço e que, em sua maior parte, não possuem laços ou redes de sociabilidade para além de seus 
territórios que Ihes permitam conduzir processos de re-territorialização em espaços seguros onde possam continuar a exercer a prática da pesca artesanal. Ainda, no limite, pode-se considerar que um cenário de mudanças climáticas implicaria praticamente na extinção da atividade em si em praticamente todo o território.

Do século XX até os dias atuais, poucas foram as políticas voltadas a estes trabalhadores que visavam modificar a situação de vulnerabilidade a que estavam submetidos (SILVA, 2004). Atualmente, uma das mais efetivas frente a esta situação é a política do Seguro-Defeso, como já mencionada anteriormente. Apesar dessa política se mostrar importante para diversas comunidades de pesca espalhadas pelo Brasil (PEREIRA; MOTA, 2015), seu foco no indivíduo e dimensão econômica, sem atingir questões e problemas estruturais do segmento artesanal, aponta para uma intrínseca limitação desta política enquanto auxílio à superação da condição de vulnerabilidade dos pescadores artesanais brasileiros (SCHMITZ et. al., 2013).

\section{As condições de vulnerabilidade dos pescadores artesanais brasileiros: uma análise a partir da PNADC}

No que tange à análise quantitativa proposta, baseada na PNADC, serão utilizadas variáveis consideradas importantes para a produção de informações sobre a vulnerabilidade dos pescadores artesanais. Dentre estas, podemos citar as dimensões raciais/étnicas e ligadas ao estatuto socioeconômico, como apontado por Cutter (2011) em sua proposta metodológica de estudo da vulnerabilidade. Enfatizarse-á também as variáveis relacionadas à infraestrutura domiciliar e urbana e ao capital humano, tais como nível de analfabetismo do grupo e maior nível de escolaridade alcançado, consideradas outras importantes dimensões de análise da vulnerabilidade (IPEA, 2018). A análise dessas variáveis será desagregada regionalmente com o intuito de não apenas analisar as condições de vulnerabilidade dos pescadores artesanais, mas examinar suas diferenças regionais.

Dentre as dimensões disponíveis apontadas como importantes para o estudo da vulnerabilidade, essas variáveis foram as escolhidas por serem consideradas as mais representativas das condições de vida dos pescadores e comunidades de pesca artesanal, percepção advinda tanto a partir da revisão bibliográfica e das informações presentes nas obras aqui utilizadas, quanto do conhecimento empírico dos autores sobre esses grupos.

Após o tratamento dos dados da PNADC anual de 2018, o total de pescadores artesanais estimado foi de cerca de 311.605, com coeficiente de variação de apenas 6\%. Deste total, 279.796 eram trabalhadores autônomos e 31.809 labutavam em regime de economia familiar, sem percepção de remuneração direta. Se comparada às estimativas do extinto Ministério da Pesca (BRASIL, 2011) que calculava cerca de um milhão de pescadores no país, com grande maioria artesanal, percebe-se que há indícios de subestimação do total de pescadores na PNADC. Acreditamos aqui que isto ocorre, em grande parte, pelas próprias características da pesquisa, que é melhor concebida para o estudo de fenômenos dispersos, como o desemprego, a natalidade, 
etc, do que para elementos concentrados, como a pesca, centrada em regiões litorâneas e ribeirinhas. Além disso, a pesquisa exclui áreas com características especiais, como Unidades de Conservação, reservas indígenas, embarcações, projetos de assentamentos rurais, entre outros (IBGE, 2019a), ou seja, alguns dos territórios com maior possibilidade de presença de pescadores - e em geral marcados pela falta de infraestrutura e acesso à serviços e de difícil acesso, o que pode reforçar a subnumeração. No entanto, mesmo com indícios dessa subestimação, as informações estimadas na PNADC para os ocupados nessa atividade demonstram coincidir com o perfil usualmente encontrado para os trabalhadores desta ocupação nos diversos estudos de caso analisados.

A distribuição dos pescadores pelas macrorregiões brasileiras indicou grande concentração destes nas regiões Norte e Nordeste, concentrando mais de $80 \%$ do total de artesanais estimados pela pesquisa (Tabela 1), percentuais muitos próximos dos encontrados na distribuição do Seguro-Defeso pelas macrorregiões (NETO, 2017), o que reforça os indícios de uma acurada estimativa da distribuição relativa de pescadores pelo país.

Tabela 1. Distribuição de pescadores artesanais pelas macrorregiões, Brasil: 2018.

\begin{tabular}{cccc}
\hline Macrorregião & Total & Desvio Padrão & Total relativo \\
\hline Norte & 123.775 & 13.334 & $39,70 \%$ \\
Nordeste & 130.499 & 12.484 & $41,89 \%$ \\
Sudeste & 37.619 & 9.514 & $12,11 \%$ \\
Sul & 13.114 & 2.830 & $4,19 \%$ \\
Centro-Oeste & 6.597 & 2.157 & $2,11 \%$ \\
\hline Brasil & 311.605 & 20.907 & $100 \%$ \\
\hline
\end{tabular}

Fonte: IBGE (2018).

Iniciando a análise do perfil dos pescadores artesanais, nota-se uma característica marcante: a predominância de pardos e pretos. É importante atentar que a realidade brasileira é marcada por um padrão de desigualdade social fundada em várias dimensões, onde o perfil racial dos grupos na população se mostra uma das mais importantes. Para grande parte da sociedade brasileira, há prevalência de processos de vulnerabilização baseados em estruturais

$$
\begin{aligned}
& \text { mecanismos de discriminação aos quais os(as) cidadãos(ãs) } \\
& \text { afrodescendentes são submetidos(as) em diferentes momentos do seu ciclo } \\
& \text { de vida e, por consequência, demarcam as desigualdades em termos de } \\
& \text { acesso ao mercado de trabalho, seja pelos rendimentos obtidos, seja em } \\
& \text { termos de acesso a oportunidades e qualidade de vida (IPEA, 2018, p. 15). }
\end{aligned}
$$

No caso dos pescadores artesanais, foi estimado um percentual de pardos e pretos de pelo menos $81 \%$ do total do grupo, ou seja, cerca de 253 mil, com 
aproximadamente $17 \%$ que se autodeclararam brancos, e, como mais uma evidência de subestimação, apenas $1 \%$ de indígenas, apesar do elevando coeficiente de variação (Tabela 2).

Tabela 2. Pescadores artesanais por raça ou cor, Brasil: 2018.

\begin{tabular}{l|ccc}
\hline Raça ou Cor & Pescadores Artesanais & $\begin{array}{c}\text { Coeficiente de } \\
\text { Variação (\%) }\end{array}$ & Porcentagem \\
\hline Branca & 53.750 & 10,93 & 17,27 \\
Preta & 40.558 & 16,88 & 13,03 \\
Amarela & 2.003 & 45,67 & 0,64 \\
Parda & 212.578 & 7,39 & 68,31 \\
Indígena & 2.296 & 40,87 & 0,74 \\
\hline
\end{tabular}

Fonte: IBGE (2018).

Além disso, a distribuição regional por raça/cor também mostrou grandes variações, demonstrando que há diversos perfis de pescadores artesanais pelo país. O Norte e Nordeste, por exemplo, apresentam entre seus trabalhadores artesanais cerca de $86 \%$ de pardos e pretos, o grupo considerado oficialmente negro. Enquanto isso, Sudeste e Centro-Oeste, tiveram pouco mais de $60 \%$ dos pescadores nessa categoria, e a região Sul apenas $24 \%$, e somente de pardos, dado que não houve registro de autodeclarados como pretos nessa região.

Historicamente, ser negro no Brasil significa viver permanentemente em condição de considerável vulnerabilidade. Logo, denotar tal pertença étnico/racial da grande maioria dos pescadores artesanais é caracterizar um dos elementos que os tornam vulneráveis frente aos riscos e perigos que os rodeiam, ao mesmo tempo que envolve também a construção de subsídios para a formulação e execução de políticas públicas voltadas à redução da vulnerabilidade.

Ao mesmo tempo, as estimativas encontradas sobre as variáveis educacionais apontam para um cenário alarmante, onde cerca de $20 \%$, aproximadamente 63 mil, dos pescadores afirmaram não saber ler e escrever (llustração 1), variável que considera como alfabetizado/a "a pessoa capaz de ler e escrever pelo menos um bilhete simples" ${ }^{1}$. Essa taxa de alfabetização ${ }^{2}$ se mostra muito superior à realidade da população brasileira acima de 15 anos de idade, cuja taxa é foi estimada pelo IBGE, através da PNADC de 2018, em cerca de 6,8\% (IBGE, 2019b), e segue em contramão

\footnotetext{
${ }^{1}$ Como se estabeleceu um recorte nesta pesquisa pela ocupação ("pescador") de pessoas de 14 anos ou mais de idade, como disposto na PNADC (IBGE, 2019a), esse índice diz respeito basicamente aos pescadores em idade ativa.

${ }^{2}$ Nesse caso não estimada por faixa ou grupo etário, mas adaptada para o universo dos trabalhadores da ocupados como pescadores artesanais, como aqui estudado.
} 
em relação ao Objetivo do Desenvolvimento Sustentável (ODS) no 4 e mais especificamente à meta 4.6 que prevê, adaptada para o Brasil, "Até 2030, garantir que todos os jovens e adultos estejam alfabetizados, tendo adquirido os conhecimentos básicos em leitura, escrita e matemática" (IPEA, 2019). Evidenciando as limitações do país ao cumprimento do ODS, ao menos em relação à esta categoria, há também grande número de pescadores, por volta de 23 mil, quase $8 \%$, que não frequentaram a escola.

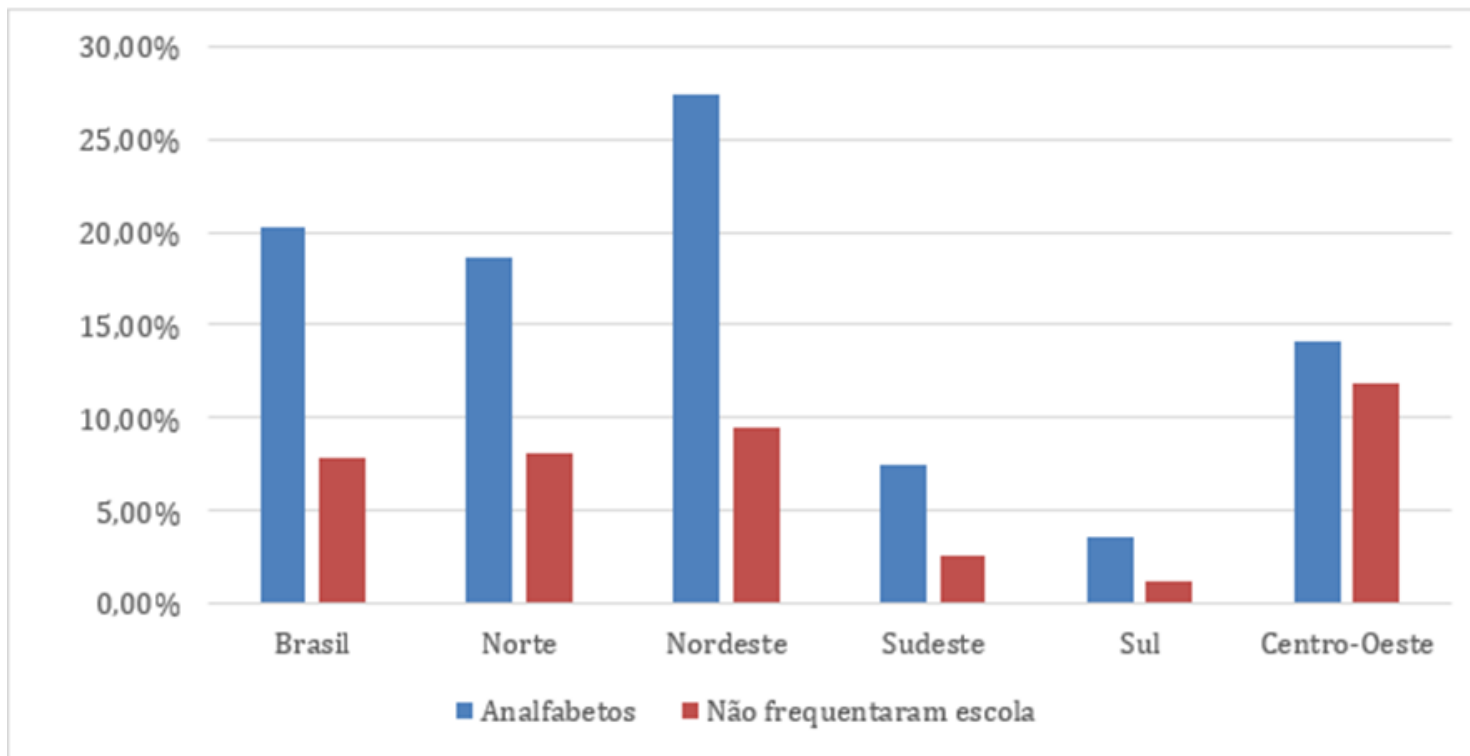

Figura 1. Percentual de pescadores artesanais analfabetos e que não frequentaram escola no Brasil e por região, Brasil: 2018. Fonte: IBGE (2018).

Apesar do alto nível de analfabetismo entre a categoria, as discrepâncias regionais se mostram altíssimas, demonstrando mais uma vez as diferentes faces da pesca artesanal no país. A constatação mais representativa dessa diferença é a indicação de grande concentração de pescadores analfabetos na região Nordeste, com cerca de $27 \%$ dos trabalhadores regionais nessa categoria. Nas maiores estimativas, após o Nordeste, aparece a região Norte, com percentual próximo da estimativa nacional. O contraste com as regiões Sudeste e Sul é enorme, com esta última apresentando percentual quase 6 vezes menor de analfabetos que o Nordeste. O percentual destes grupos que não frequentaram escola também apresenta desigualdades regionais, porém em menor dimensão.

Em conformidade com esse quadro, a análise do nível de instrução formal mais alto alcançado mostra que pouco mais de $11 \%$ deste grupo não frequentou escola ou, se frequentou, teve menos de um ano de estudo (Tabela 3). Além disso, uma esmagadora maioria destes trabalhadores não passaram do nível fundamental, cerca de $84 \%$ do total, enquanto $78 \%$ do total nem completaram esse nível. Dessa maneira, pouco mais de $15 \%$ deste universo chegou ao nível médio e, apesar do desvio padrão aumentar consideravelmente nestas estimativas de menor valor, menos de $9 \%$ terminaram o ensino médio. Devido a maior complexidade desse quesito e à 
abordagem regional já realizada no que toca a questão educacional, não foi feita uma desagregação e análise por região destes dados.

Tabela 3. Nível de instrução mais elevado alcançado pelos pescadores artesanais, Brasil: 2018

\begin{tabular}{|c|c|c|c|c|}
\hline $\begin{array}{l}\text { Nível de instrução mais } \\
\text { alto alcançado }\end{array}$ & Pescadores & $\begin{array}{c}\text { Coeficiente } \\
\text { de Variação } \\
(\%)\end{array}$ & Porcentagem & $\begin{array}{l}\text { Porcentagem } \\
\text { Acumulada }\end{array}$ \\
\hline $\begin{array}{l}\text { Sem instrução e menos de } \\
1 \text { ano de estudo }\end{array}$ & 34.970 & 13,40 & 11,22 & 11,22 \\
\hline $\begin{array}{c}\text { Fundamental incompleto ou } \\
\text { equivalente }\end{array}$ & 208.266 & 7,37 & 66,84 & 78,06 \\
\hline $\begin{array}{c}\text { Fundamental completo ou } \\
\text { equivalente }\end{array}$ & 21.190 & 15,13 & 6,80 & 84,86 \\
\hline $\begin{array}{l}\text { Médio incompleto ou } \\
\text { equivalente }\end{array}$ & 19.726 & 18,47 & 6,33 & 91,19 \\
\hline $\begin{array}{l}\text { Médio completo ou } \\
\text { equivalente }\end{array}$ & 26.894 & 13,93 & 8,63 & 99,82 \\
\hline $\begin{array}{l}\text { Superior incompleto ou } \\
\text { equivalente }\end{array}$ & 365 & 66,99 & 0,12 & 99,94 \\
\hline Superior completo & 195 & 100,02 & 0,06 & 100,00 \\
\hline
\end{tabular}

Fonte: IBGE (2018).

Ao atentarmos para os riscos e perigos associados à vida cotidiana dos pescadores artesanais descritos anteriormente, entende-se que o capital humano é fundamental para a construção da sua capacidade de resposta e resiliência. Saber ler e escrever é condição mínima para que os pescadores possam autonomamente ocupar espaços de participação e decisão sobre os seus territórios de vida. Para enfrentar processos de degradação ambiental, especulação imobiliária, conflitos fundiários, contaminação industrial etc., sem necessitar da tutela de outros atores, a escolarização desse grupo torna-se essencial. Além disso, a construção autônoma de alternativas frente aos perigos em questão passa fundamentalmente pelas oportunidades que somente lhes são oferecidas a partir do ensino formal.

Em relação à dimensão econômica, os pescadores comumente são caracterizados como populações com pobreza monetária (BÉNÉ; FRIEND, 2011), apesar de não poderem ser enquadrados em diversas definições deste termo, como a de Jannuzzi e Fonseca (2017). Entretanto, o baixo rendimento do trabalho é uma característica marcante da categoria dos pescadores artesanais, como demonstram os dados da PNADC. O rendimento declarado por $\operatorname{eles}^{3}$ ao longo de 2018 teve uma média de

\footnotetext{
${ }^{3}$ Apenas para os pescadores artesanais que trabalhavam por conta própria, já que os em regime de economia familiar não apresentavam rendimento.
}

REVISTA GEONORTE, V.11, N.38, p.162-185, 2020.

DOI: 10.21170/geonorte.2020.V.11.N.38.162.185

(ISSN 2237 - 1419) 
$R \$ 547,92$, com desvio padrão de $R \$ 24,91$, e mediana de $R \$ 400,00$. O primeiro quartil foi estimado em $R \$ 200,00$ e o terceiro, em $R \$ 750,00$. Distribuídos em faixas de rendimento, pouco mais de $55 \%$ dos pescadores receberam até meio salário mínimo ${ }^{4}$ (SM) e quase $85 \%$ demonstraram receber menos de um salário mínimo (Figura 2).

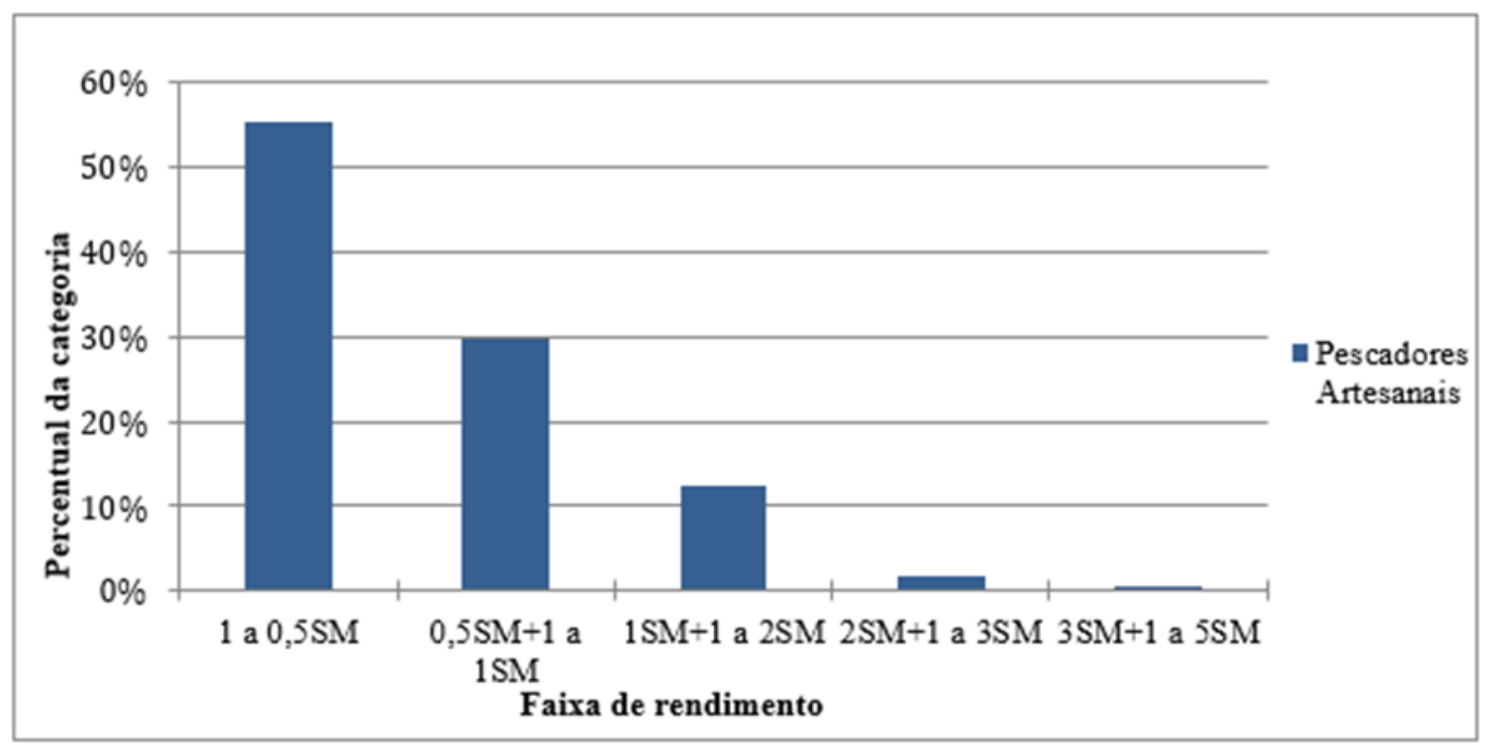

Figura 2. Pescadores artesanais, por faixa de rendimento em SM oriundos do trabalho principal, Brasil: 2018. Fonte: IBGE (2018).

O primeiro e terceiro quartil foram estimados, respectivamente, em $\mathrm{R} \$ 200,00$ e $\mathrm{R} \$ 1.000,00$. Enquanto isso o rendimento efetivo domiciliar per capita apresentou valor médio de $R \$ 494,53$ e desvio padrão de $R \$ 26,15$, o que pode indicar número considerável de dependentes nas famílias dos pescadores.

Além disso, uma análise nos dados desagregados por região evidenciou mais uma vez uma grande discrepância no país. As regiões Norte e Nordeste apresentaram o maior percentual de pescadores com menores níveis de renda. Nestas regiões mais de $60 \%$ deste grupo recebia até meio salário mínimo e $90 \%$ até um salário. Em comparação, as regiões Sudeste e Sul demonstraram ter, respectivamente, cerca de $45 \%$ e $60 \%$ deste grupo recebendo mais de um salário mínimo (Figura 3).

${ }^{4}$ O salário mínimo em 2018 era de $\mathrm{R} \$ 954,00$ (BRASIL, 2017). 


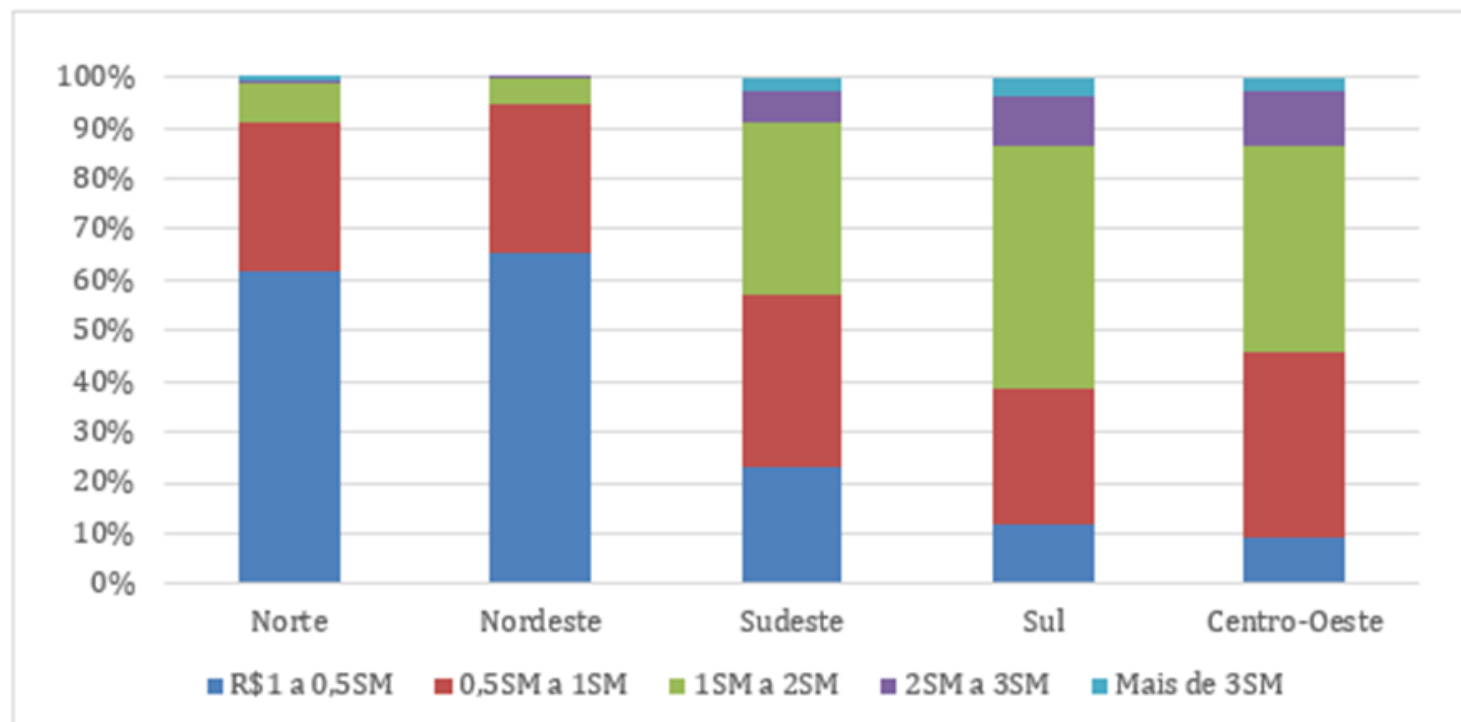

Figura 3. Percentual de Pescadores das macrorregiões por faixa de renda, em salários mínimos (SM), Brasil: 2018. Fonte: IBGE (2018).

Assim como no caso do capital humano associado à alfabetização e escolarização desse grupo, tem-se a baixa renda dos pescadores artesanais como mais uma característica que evidencia sua vulnerabilidade, tal como apontado pela literatura (IPEA, 2018). Recursos monetários escassos significam uma luta diária pela sua própria sobrevivência e reprodução enquanto grupo. Frente aos perigos descritos em seção anterior, tal condição vulnerável acentua-se consideravelmente. Como lidar com o risco da morte no mar, da redução dos estoques pesqueiros, da degradação ambiental, da perda de seus territórios para especuladores imobiliários e para 0 Estado, da constituição de zonas de exclusão de pesca, das mudanças climáticas etc., sem auferir renda suficiente para enfrentá-los de diversas formas possíveis (migrando, judicializando os conflitos, reconstruindo suas casas e petrechos de pesca, equipando melhor os seus barcos, construindo propostas alternativas, etc.)?

Além disso, implicado nesse quesito monetário está a questão racial, indicando um padrão de concentração de menor renda entre os grupos de pescadores artesanais com maior proporção de negros. Assim, uma análise regional baseada nesses dois quesitos aponta uma concentração alta de negros nas regiões com renda oriunda da atividade pesqueira mais baixa. Nesse caso, o Nordeste, com $67 \%$ de pardos e $19 \%$ de negros, apresenta a menor renda média mensal regional, de $\mathrm{R} \$ 400,25$, acompanhada de perto pelo Norte, com $82 \%$ de pardos e $11 \%$ de negros, e renda média de $\mathrm{R} \$ 464$ (Figura 4). Os pescadores das regiões com maior percentual de brancos do país, Sul e Sudeste, apresentam mais que o dobro de renda média mensal das regiões mais pobres. No caso do Sul, esse valor chega a mais de três vezes a renda média do Nordeste. 


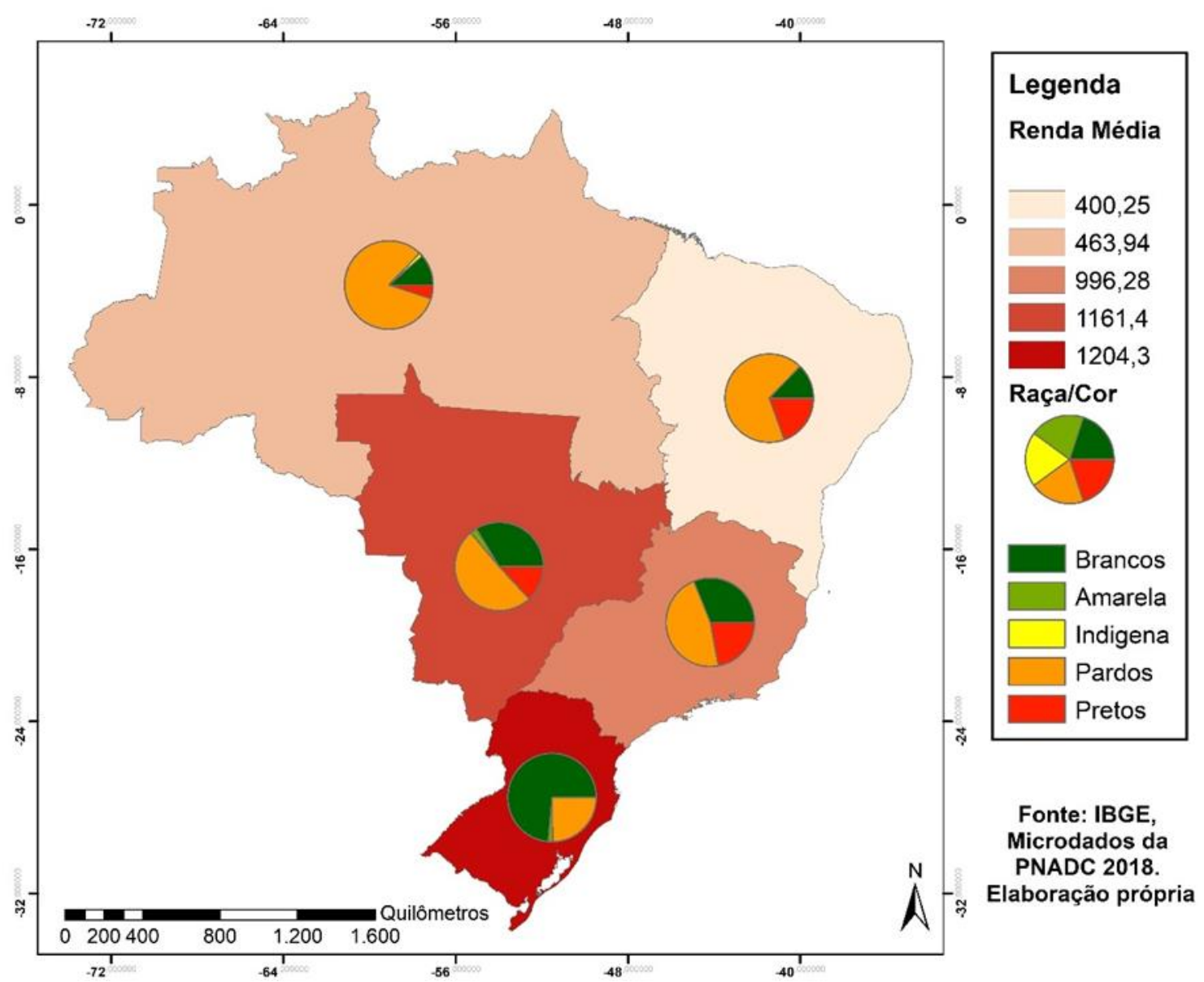

Figura 4. Proporção de pescadores por raça/cor e Renda média oriunda do trabalho de pescador artesanal por macrorregiões, Brasil: 2018.

Estabelecendo diálogo entre a perspectiva da vulnerabilidade sociodemográfica, é importante abordar a dimensão da infraestrutura urbana e dos domicílios dos pescadores artesanais.

Apesar das promessas trazidas pelas benesses da urbanização no que tange às condições de vida de grupos vulneráveis, tem-se que os trabalhadores da pesca artesanal apresentam reduzido acesso à estrutura da rede urbana em seus domicílios. Em 2018, apenas 61\%, pouco mais de 192 mil, tinham abastecimento de água por rede geral de distribuição; 53\%, em torno de 166 mil, tinham lixo coletado em casa por serviço de limpeza; e somente $21,8 \%$, cerca de 65 mil, dos pescadores tinham domicílios ligados à rede coletora de esgoto. Os valores são consideravelmente mais baixos que a média nacional encontrada para o mesmo ano pela PNADC, estimada em $84,9 \%, 82,1 \%$ e $64,8 \%$, respectivamente (Figura 5), o que reforça consideravelmente sua condição de vulnerabilidade frente aos riscos elencados anteriormente, condição esta que nos parece ser praticamente generalizada para esse grupo. 


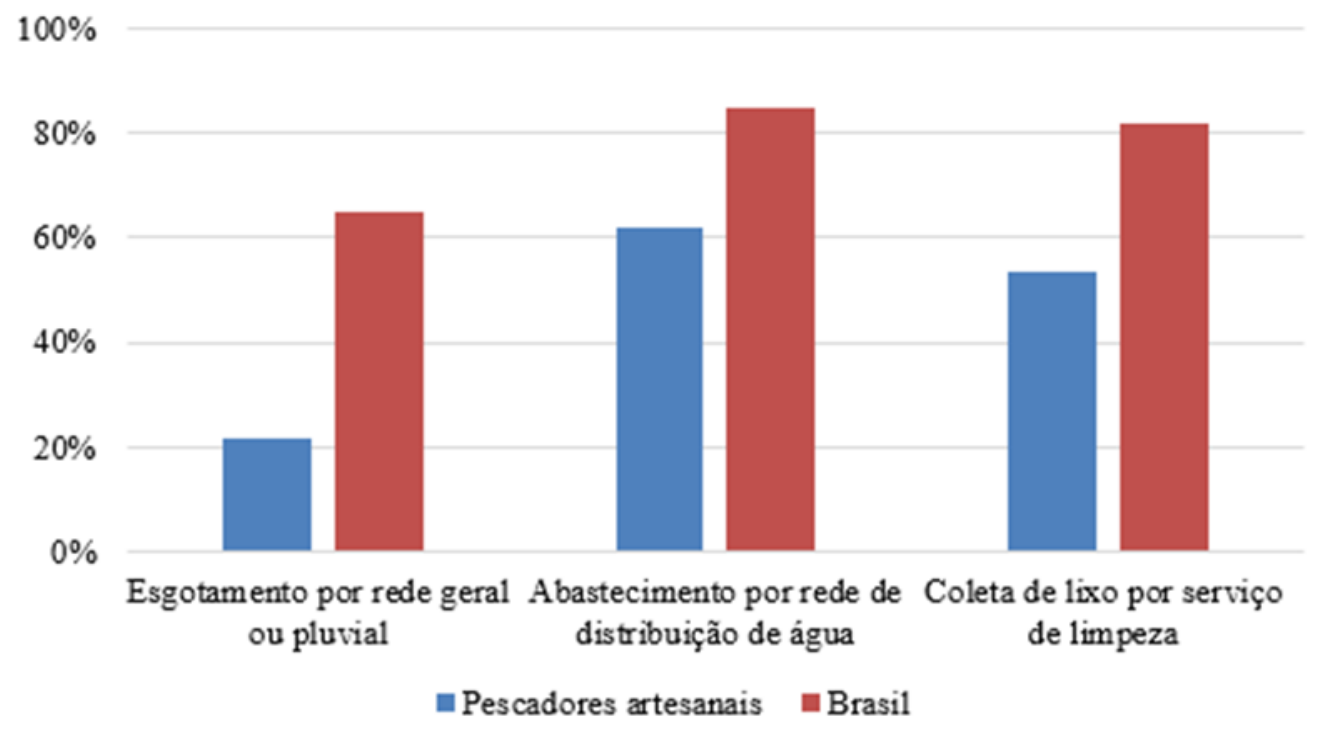

Figura 5. Percentual de pescadores artesanais e da população brasileira com acesso à infraestrutura urbana no domicílio, Brasil: 2018. Fonte: IBGE (2018).

Mais uma vez, a análise regional demonstra diferenças significativas deste grupo. Nesse caso, a região Norte desponta como a com menor percentual de acesso a esses três serviços urbanos. Além da baixa proporção de ligação à rede de distribuição de água, a coleta de lixo no domicílio por serviço de limpeza e o acesso à rede de esgoto também se mostram profundamente desigual (Figura 6), apesar de, neste último quesito, a disparidade em relação a região Sul ser menor que em outras variáveis. O Nordeste também desponta como uma das regiões com menor acesso aos serviços.

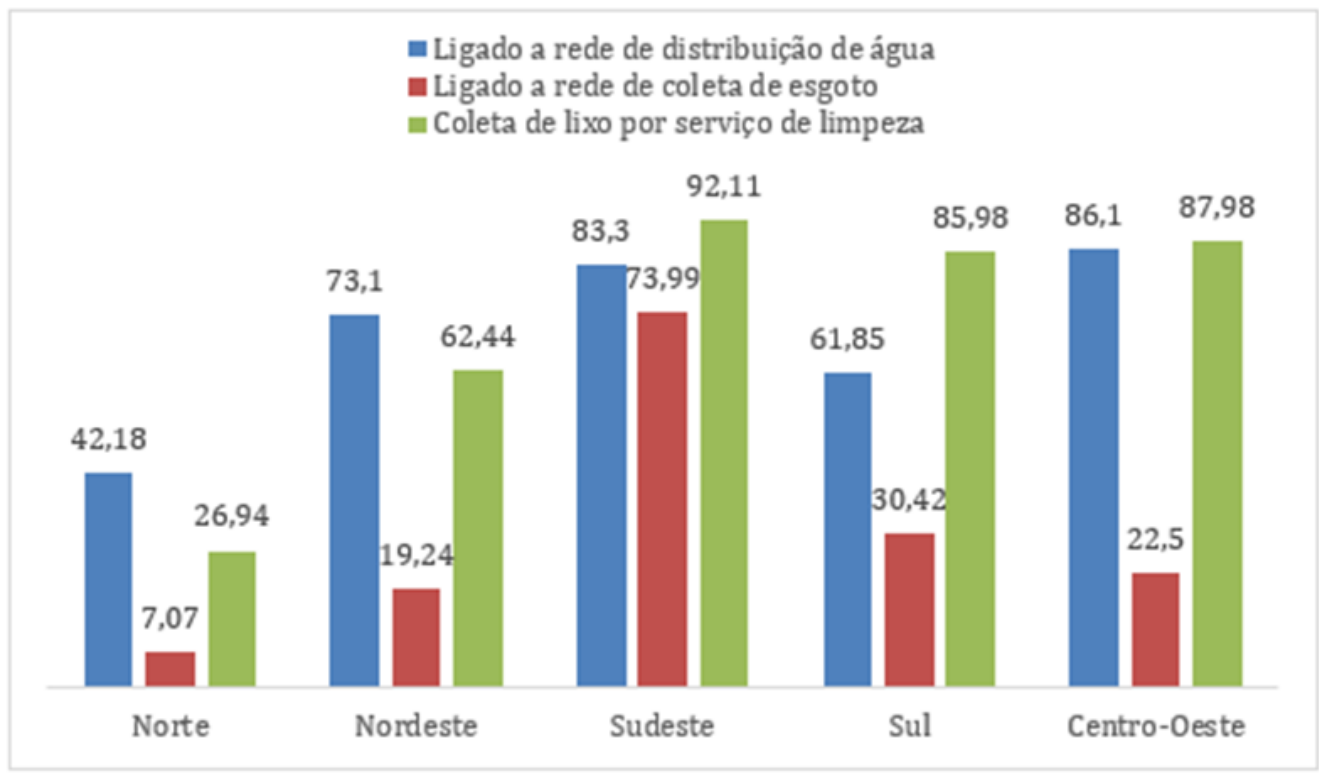

Figura 6. Pescadores artesanais residentes em domicílios com acesso a serviços urbanos por macrorregião brasileira, Brasil: 2018. Fonte: IBGE (2018). 
A análise dessas variáveis apontou desigualdades regionais que sobressaem, indicando condições de vulnerabilidade distintas, mais aprofundadas principalmente nas regiões Norte e Nordeste, porém presentes dentre os pescadores artesanais de todo o território brasileiro. Essas condições, no entanto, representam apenas retratos de um determinado aspecto em um dado momento, apresentando maior potencial se entendidas de forma complementar e dialética aos processos de vulnerabilização, ou seja, aos intermitentes movimentos que tensionam e ameaçam a reprodução social da pesca artesanal no país.

Dessa forma, a percepção de que os pescadores artesanais das regiões Norte e Nordeste apresentam maiores índices de analfabetismo, menor renda média, menor acesso à infraestrutura e serviços urbanos, maior proporção de negros, indicam, dentro da categoria dos pescadores artesanais do país e de toda a sociedade brasileira, um maior nível de vulnerabilidade. Ao menos dentre as dimensões passíveis de mensuração, estes são indicadores que reforçam o perfil vulnerável destes sujeitos e as desigualdades regionais dentre o próprio grupo.

Assim, apesar de suas características de rendimento econômico não permitirem categorização enquanto pobreza monetária, normalmente estabelecidas em rendimentos abaixo de $\mathrm{U} \$ 1,50$ a $U \$ 1,90$ diário per capita ${ }^{5}$ ou valor próximo (JANNUZZI et al, 2014), o quadro de vulnerabilidade dos pescadores, marcado pela privação de bens e, principalmente, serviços, debilidade na dimensão educacional, e forte componente racial, inclusive se aproximando em diversos parâmetros à pobreza multidimensional (JANNUZZI, FONSECA, 2017), faz com que a capacidade de resposta e resiliência frente aos processos de vulnerabilização dos ocupados neste ofício seja seriamente comprometida.

\section{CONCLUSÃO}

O presente artigo objetivou analisar as características e condições de vida dos pescadores artesanais brasileiros, à luz da vulnerabilidade.

São diversos os riscos a que esses trabalhadores estão submetidos. Riscos esses que, no limite, configuram perigos consideráveis, envolvendo a impossibilidade da sua própria reprodução social e cultural. De um lado, o risco de "morrer no mar", os associados à redução do estoque pesqueiro causada pela degradação ambiental e pela pesca industrial, a urbanização/metropolização, a especulação imobiliária, a industrialização, as mudanças climáticas, entre outros, são processos desigualmente distribuídos no território que afetam de forma brutal essa população, acentuando a sua vulnerabilidade.

Esse grupo, historicamente, apresenta características elementares que configuram uma condição considerável de vulnerabilidade, como o artigo buscou evidenciar. A

\footnotetext{
${ }^{5}$ Atualmente, cerca de $\mathrm{R} \$ 5$ diários ou $\mathrm{R} \$ 150$ mensais per capita
} 
forte composição negra - em uma sociedade profundamente marcada pela questão racial -, a alta taxa de analfabetismo, a baixa escolaridade, a baixa renda e a falta de acesso à infraestrutura urbana que caracterizam os pescadores artesanais brasileiros são condições que iluminam o fato de que esses grupos, ao mesmo tempo em que são afetados por uma série de processos que tendem a inviabilizar a sua existência, possuem poucos ou nenhum recurso - material e simbólico - para enfrentar os perigos que cercam suas vidas cotidianas, ou mesmo para adaptar-se aos mesmos. Assim, as condições e processos de vulnerabilização que, a princípio, não possuem mensuração, como os conflitos ambientais, a disputa por território e por recursos naturais travada com diversos atores, entre eles a pesca industrial, a especulação imobiliária, empreendimentos turísticos e empresa petrolíferas, tem suas nefastas consequências aprofundadas para pelas características de seus trabalhadores.

Dessa forma, uma análise integrada, de caráter regional, das condições dos pescadores artesanais e dos processos de vulnerabilização indica que, apesar do quadro de vulnerabilidade geral da categoria, há contradições e disparidades entre regiões. Assim, se, por exemplo, os pescadores da região Sul e Sudeste apresentam condições de vulnerabilidade menos agudas que os do Norte e Nordeste, por outro, aqueles muitas vezes estão mais expostos a processos de vulnerabilização ligado ao espaço urbano, como atividades portuárias, industriais, degradação ambiental, entre outras, ainda muito centradas no eixo Sul-Sudeste do país. Um outro preocupante indício, no entanto, é que a rápida expansão dessas atividades para aquelas regiões - Norte e Nordeste - acentuada nas últimas décadas, encontra populações artesanais em condições mais críticas, potencializando a capacidade de desorganização destas comunidades tradicionais, como o caso recente do derramamento de óleo, com consequências a serem analisados ao longo dos anos. Esta análise demonstra e reforça também a percepção da existência múltiplos "brasis" em nosso país, mesmo entre esses grupos categorizados como populações tradicionais, frequentemente analisados de forma homogeneizante.

Com o objetivo de estudar esses diferentes povos e características do Brasil, o recorte desenvolvido no presente artigo, até então pouco explorado na literatura acadêmica, pode se constituir como um instrumento importante. Além disso, seu emprego pode oferecer subsídios importantes para análise e avaliação de políticas públicas direcionadas ao setor e seus trabalhadores. Da mesma forma, pode ser ferramenta útil na produção de pesquisas acerca da pesca artesanal nas diferentes Unidades da Federação, sua distribuição no território dos Estados, nas Capitais e Regiões Metropolitanas, nos meios urbano e rural, além de permitir estudos de gênero, relações étnico-raciais, geracionais, entre outros. Todas estas são desagregações possíveis de realização na PNADC e em outras pesquisas do IBGE, como o Censo Demográfico e a Pesquisa de Orçamentos Familiares. Ambas pesquisas possuem as mesmas variáveis que aqui permitiram o recorte dos trabalhadores ocupados na pesca artesanal.

As políticas públicas a serem pensadas para esses grupos devem atentar para a complexidade que os envolve, inclusive a espacial. Cada dimensão importa - e não somente a renda, que foi o alvo das políticas mais recentes voltadas para a pesca 
artesanal. Tais dimensões devem ser analisadas caso a caso em profundidade, colocando em relevo a condição de vulnerabilidade desses trabalhadores, as causas e origens desse estado e os processos de vulnerabilização. Para enfrentar e superar a vulnerabilidade, é imprescindível enfatizar os riscos, perigos e todos os processos que levam à reprodução de tal condição vulnerável.

Espera-se que este artigo seja uma inspiração e ponto de partida para a construção de um olhar mais aprofundado, complexo e sensível a esses sujeitos tão fundamentais para a nossa existência enquanto sociedade brasileira. Finalizamos este trabalho, portanto, ressaltando sua importância para 0 estudo desta população e, consequentemente, sua aplicabilidade no planejamento e execução de políticas que visem enfrentar a situação de vulnerabilidade desses trabalhadores brasileiros. Situação que, devido às circunstâncias atuais, com o derramamento de óleo de grandes proporções na costa brasileira, merecerá grande atenção nos próximos anos.

\section{REFERÊNCIAS}

ACSELRAD, H. Vulnerabilidade ambiental, processos e relações. Encontro Nacional de Produtores e Usuários de Informações Sociais, Econômicas e Territoriais, II. Anais... Rio de Janeiro: IBGE, 2006.

ACSELRAD, H. Ambientalização das lutas sociais: o caso do movimento por justiça ambiental. Estudos avançados, v. 24, n. 68, pp. 103-119, 2010.

ACSELRAD, H. Vulnerabilidade social, conflitos ambientais e regulação urbana. $O$ social em questão, ano XVIII, n. 33, 2015, p. 57-68, 2015.

ALMEIDA, A.; KAN, L. Vulnerabilidade Sócio Ambiental de Pescadores e Marisqueiras em S. Francisco do Conde/Ba. Fronteiras: Journal of Social, Technological and Environmental Science, v.5, n.2, p. 29-46, 2016.

ARAÚJO, I. X.; SASSI, R.; LIMA, E. R. V. Pescadores artesanais e pressão imobiliária urbana: Qual o destino dessas comunidades tradicionais? Revista de Gestão Costeira Integrada, v. 14, n. 3, p. 429-446, set. 2014.

BÉNÉ, C.; FRIEND, R. M. Poverty in small-scale fisheries: old issue, new analysis. Progress in Development Studies, v. 11, n. 2, p. 119-144, 2011.

BRASIL. Lei no 11.959, de 29 de junho de 2009. Dispõe sobre a Política Nacional de Desenvolvimento Sustentável da Aquicultura e da Pesca e dá outras providências. Brasília: Congresso Nacional, 2009.

BRASIL. Boletim Estatístico da Pesca e Aquicultura 2011. Brasília: Ministério da Pesca e Aquicultura, 2011. 
A VULNERABILIDADE DOS PESCADORES ARTESANAIS BRASILEIROS: UMA ANÁLISE SOCIODEMOGRÁFICA

BRASIL. Decreto n‥ 9.255, de 29 de dezembro de 2017. Regulamenta a Lei no 13.152, de 29 de julho de 2015, que dispõe sobre o valor do salário mínimo e a sua política de valorização de longo prazo. Brasília: Presidência da República, 2017.

CASTRO, S. D. A. Riesgos y peligros: una visión desde la Geografía. Scripta Nova: Revista Electrónica de Geografía y Ciencias Sociales. Barcelona, n. 60, 2000.

CUTTER, S. A ciência da vulnerabilidade: modelos, métodos e indicadores. Revista Crítica de Ciências Sociais, n. 93, p. 59-69, Jun. 2011.

DIAS NETO, J. Gestão do uso dos recursos pesqueiros marinhos no Brasil. Brasília: Ibama, 2010. ISBN: 85-7300-150-X.

DIAS NETO, J. Análise do seguro-desemprego do pescador artesanal e de possíveis benefícios para a gestão pesqueira. Brasília: IBAMA, 2017, 120 p.

DIEGUES, A. C. Pescadores, camponeses e trabalhadores do mar. São Paulo: Ed. Àtica, 1983.

DIEGUES, A. C. A pesca construindo sociedades: leituras em antropologia marítima e pesqueira. São Paulo: NUPAUB/USP, 2004.

FARACO, L. F. D.; ANDRIGUETTO FILHO, J. M.; DAW, T.; LANA, P. da C.; TEIXEIRA, C. F. Vulnerabilidade de pescadores no litoral sul do Brasil e sua relação com áreas marinhas protegidas em um cenário de declínio da pesca. Revista Desenvolvimento e Meio Ambiente, v. 38, p. 51-76, 2016.

FAUSTINO, C.; FURTADO, F. Indústria do Petróleo e Conflitos Ambientais na Baía de Guanabara: o caso do Comperj. Rio de Janeiro: Dhesca, 2013.

FIX, M. Financeirização e transformações recentes no circuito imobiliário no Brasil. Campinas: UNICAMP, 2011. 263 f. Tese (Doutorado em Economia) - Programa de Pós-Graduação em Desenvolvimento Econômico, Instituto de Economia, Universidade Estadual de Campinas, Campinas, 2011.

I

NSTITUTO BRASILEIRO DE GEOGRAFIA E ESTATÍSTICA - IBGE. Pesquisa Nacional por Amostra de Domicílios Contínua. Notas técnicas Versão 1.5. 4르 ed. Rio de Janeiro: IBGE, 2019a.

INSTITUTO BRASILEIRO DE GEOGRAFIA E ESTATÍSTICA - IBGE. Educação 2018. PNAD Contínua. Rio de Janeiro: IBGE, 2019b.

INSTITUTO BRASILEIRO DE GEOGRAFIA E ESTATÍSTICA - IBGE. Pesquisa Nacional por Amostra de Domicílios Contínua - 2018. Microdados. Rio de Janeiro, s.d. 
A VULNERABILIDADE DOS PESCADORES ARTESANAIS BRASILEIROS: UMA ANÁLISE SOCIODEMOGRÁFICA

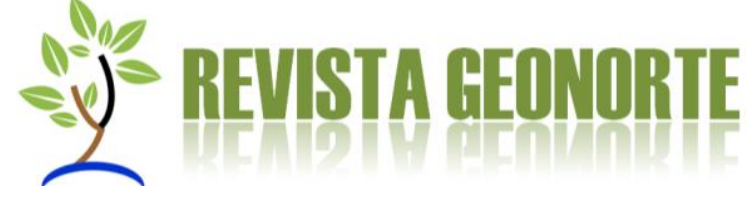

INSTITUTO DE PESQUISA ECONÔMICA APLICADA - IPEA. Métodos e conceitos para o cálculo do índice de vulnerabilidade social com base nas PNADs e desagregações. Brasília: IPEA, 2018.

INSTITUTO DE PESQUISA ECONÔMICA APLICADA - IPEA. ODS4. Educação de Qualidade. 2019. Disponível em: <http://www.ipea.gov.br/ods/ods4.html>. Acesso em: 12/11/2019.

JANNUZZI, P. M.; FONSECA, J. C. G. Pobreza monetária e multidimensional no brasil: Estimativas aprimoradas para análise do papel das políticas sociais de 1992 a 2014. Revista Ciências do Trabalho, n. 7, abril 2017.

JANNUZZI, P.M et al. Dimensionamento da extrema pobreza no Brasil: aprimoramentos metodológicos e novas estimativas. In: CAMPELLO, T.; SILVA, T. F.; COSTA, P. V. (Orgs.). O Brasil Sem Miséria. 1ed. Brasilia: MDS, 2014, p. 763-791.

LENCIONI, S. Metropolização do espaço: processos e dinâmicas. In: FERREIRA, A. et. al (orgs.). Metropolização do espaço: gestão territorial e relações urbano-rurais. Rio de Janeiro: Consequência, 2013, p. 17-34.

MARANDOLA JR., E; HOGAN, D. J. Vulnerabilidade e riscos: entre Geografia e Demografia. Revista Brasileira de Estudos de População. São Paulo, v. 22, n. 1, 2005, pp. 29-53.

MARANDOLA JR., E; HOGAN, D. J. As dimensões da vulnerabilidade. São Paulo em perspectiva, v. 20, 2006, pp. 33-43.

MARANDOLA JR., E; HOGAN, D. J. Vulnerabilidade do lugar vs. vulnerabilidade sociodemográfica: implicações metodológicas de uma velha questão. Revista Brasileira de Estudos de População, v. 26, 2009, pp. 161-181.

OLIVEIRA, O. M. B. A. de; SILVA, V. L. da. O processo de industrialização do setor pesqueiro e a desestruturação da pesca artesanal no Brasil a partir do Código de Pesca de 1967. Sequência, 2012, n. 65, p. 329-357.

PEDROSA, B. M.; LIRA, L.; MAIA, A. L. Pescadores urbanos da zona costeira do Estado de Pernambuco, Brasil. Boletim do Instituto de Pesca, São Paulo, v.39, n. 2, p. 93-106, 2013.

PEREIRA, J. A.; MOTA, D. M. De lavradores a pescadores artesanais: camponeses. Cadernos CERU, v. 26, n. 2, 2015.

RAMALHO, C. W. N. Estado, pescadores e desenvolvimento nacional. Da reserva naval à aquícola. Ruris, v. 8, n. 1, p. 31-62, mar. 2014. 
RIBEIRO, I.; CASTRO, A. C. L. Pescadores artesanais e a expansão portuária na praia do Boqueirão, llha de São Luís-MA. Revista de Políticas Públicas, v. 20, n. 2,p. 864-884, 2016.

RODRIGUES, L. C. Turismo, empreendimentos imobiliários e populações tradicionais: conflitos e interesses em relação à propriedade da terra. Civitas - Revista de Ciências Sociais, Porto Alegre, v. 10, n. 3, 2010, p. 527-544.

SANTOS, M. Sociedade e espaço: a formação como teoria e como método. Boletim Paulista de Geografia, n. 54, p. 81-99, 1977.

SEAP/PR - Secretaria Especial de Aquicultura e Pesca. Programa Pescando Letras. Brasília: Governo Federal, 2005, 34p.

SCHMITZ, H.; MOTA, D. M.; PEREIRA, J. A. Pescadores artesanais e Seguro Defeso: Reflexões sobre processos de constituição de identidades numa comunidade ribeirinha da Amazônia. Revista de Antropologia (Online), v. 5, n. 1, p. 116-139, 2013.

SILVA, C. A. da. Política Pública e Território: passado e presente da efetivação de direitos dos pescadores artesanais no Brasil. Rio de Janeiro: Consequência, 2015.

SILVA, P. P. da. From common property to co-management: lessons from Brazil's first maritime extractive reserve. Marine Policy, v. 28, n. 5, p. 419-428, 2004.

UCHÔA, V. 'Ninguém quer o que pescamos': o drama dos pescadores com o petróleo no litoral da Bahia. BBC News Brasil, Salvador, Out. 2019. Disponível em: < https://www.bbc.com/portuguese/brasil-50158823>. Acesso em: 20 de nov. 2019.

UCHÔA, V. Danos do óleo no litoral do Nordeste vão durar décadas, dizem oceanógrafos. BBC News Brasil, Salvador, Out. 2019. Disponível em: < https://www.bbc.com/portuguese/brasil-50131560>. Acesso em: 24 nov. 2019. 